\title{
FIELD OBSERVATIONS ON FLYING FISHES; A SUGGESTION OF METHODS
}

\author{
BY C. M. BREDER, JR. \\ New York Aquarium
}

\section{INTRODUCTION}

(Figs. 301-305 incl.)

Ichthyologists and laymen alike when aboard ship frequently make passing observations on the various species of flying fishes that dart away from the prow of their vessel. Aside from speculations on the mechanism of the Exocoectid flight most of these observations have been exceedingly desultory and likely few persons have considered that a little systematizing of them could be of scientific value. ${ }^{1}$ As opportunities for such studies come at a time when it is often impossible to pursue other matters of interest they become useful adjuncts to practically any one for whom it is necessary to travel on the high seas. The purpose of this paper is to call attention to the kind of data that would be valuable to gather and to describe a systematic method for gathering it. The suitability of this method is demonstrated by results obtained on a single short trip. These results are recorded more for their suggestiveness than otherwise as only by repeated observations of this sort can a proper answer be given to the questions they reopen or originate.

\section{MethodS}

The observations that may be made from the deck of an ordinary commercial carrier divide themselves roughly into three interrelated parts. For our purposes here they may be described separately, as follows.

\section{DISTRIBUTION}

Data of value concerning the distribution of the family Exocoetidae may be augmented by statistical counts of the numbers set into flight by the vessel carrying the observer. A suitable place

1 Scientific literature contains many incidental references to observations on flying fish but for our purposes here it is thought superfluous to refer to them in any detail for none shows any attempt to make systematic observations which is the method under consideration. 
on the vessel should be selected where all set in flight on one side of the ship may be seen. This will be found, usually, to be some place along the top deck about one-quarter of the ship's length from the prow. Incidentally it has the advantage of being fairly out of the way of over-talkative fellow passengers who usually crowd ahead of that point to wonder at the flying fish or the play of porpoises. At such a point the observer stations himself for a stated period and counts the number of fish raised. Then immediately following he stations himself on the other side of the ship for an identical period to remove any possible bias. The importance of making such bilateral counts will be brought out later. In counting, it is well to write down the numbers seen in a school and the single fish separately. For convenience it is worth while to have some sort of a form that can be filled out as the observations are made. Such a form is illustrated (Fig. 301, A). For all this work it is necessary to have certain data abstracted from the ship's log. Officers of the vessels are usually highly interested in accommodating one in such a matter. For this purpose another form is advisable. This is shown (Fig. 301, B). It is desirable, but not essential, to have a chart of the waters being navigated so that the course may be taken directly from that of the ship.

The data accumulated by this method throws light on many interesting questions besides those of distribution. These will be illustrated by the studies used for a basis of the present paper.

\section{IDENTIFICATION}

The field identification of flying fishes is not always an easy matter but when they can be determined, it, of course, greatly enhances the value of any such observations. The wing patterns, naturally, are of considerable significance in this connection. It was found to be a help to have outlines prepared on which patterns could be sketched for future reference. Colored pencils should be a help. Figure 301, C illustrates the forms used in this connection. High-powered field glasses proved to be of little value in this connection as the time elapsed in bringing them to bear on the object generally was so long that the distance the fish covered more than compensated for the advantage of the glasses. Possibly greater skill in their manipulation would prove them to be of very definite value. 


\section{FLIGHT}

Any data on the length of time elapsed, distance covered, etc., in flight is always of interest, especially when made in regard to weather and other conditions. A good stop watch is a necessary instrument to have with one for such observations. Figure 301, D illustrates a form used for tabulating flight data. In all cases the size of the fish should be estimated as carefully as possible.

The above bare outline gives an idea of the type of observations that may be made aboard ship without any elaborate preparations and whereby otherwise idle time may be rendered of scientific value.

The suggested complete equipment is as follows:

One good time piece

One good stop watch

One pair of field glasses

Forms for distribution count

Forms for ship's log data

Forms for sketching wing patterns

Forms for timing flights
One loose leaf notebook for holding above and spare sheets for miscellaneous notes

Colored and black pencils

One good chart of area

One ruler and protractor for plotting chart

The forms if made out in accordance with the accompanying figures will help prevent the omission of important data and it is strongly recommended that they be of some standard sized loose leaf pocket note book. Those illustrated measure $33 / 4^{\prime \prime} \times 634^{\prime \prime}$. An ordinary mimeograph may be employed to prepare them.

\section{ANALYSIS OF DATA}

The data obtained in the manner described is of cumulative value and subject to various analysis. Its arrangement has consequently been so planned as to allow of its fullest analytical utilization. Some of the questions it is hoped that this method will shed light on follow:

Distribution of the Exocoetidae in reference to temperature, season, current, latitude and longitude, size of fish, etc.

Length, direction, height, etc., of flight of Exocoetidae in reference to wind direction and force, temperature, sea, size of fish, etc.

Field identification of Exocoetidae and eventually distribution of species.

Sizes of Exocoetidae and eventually supplementary data on growth. 

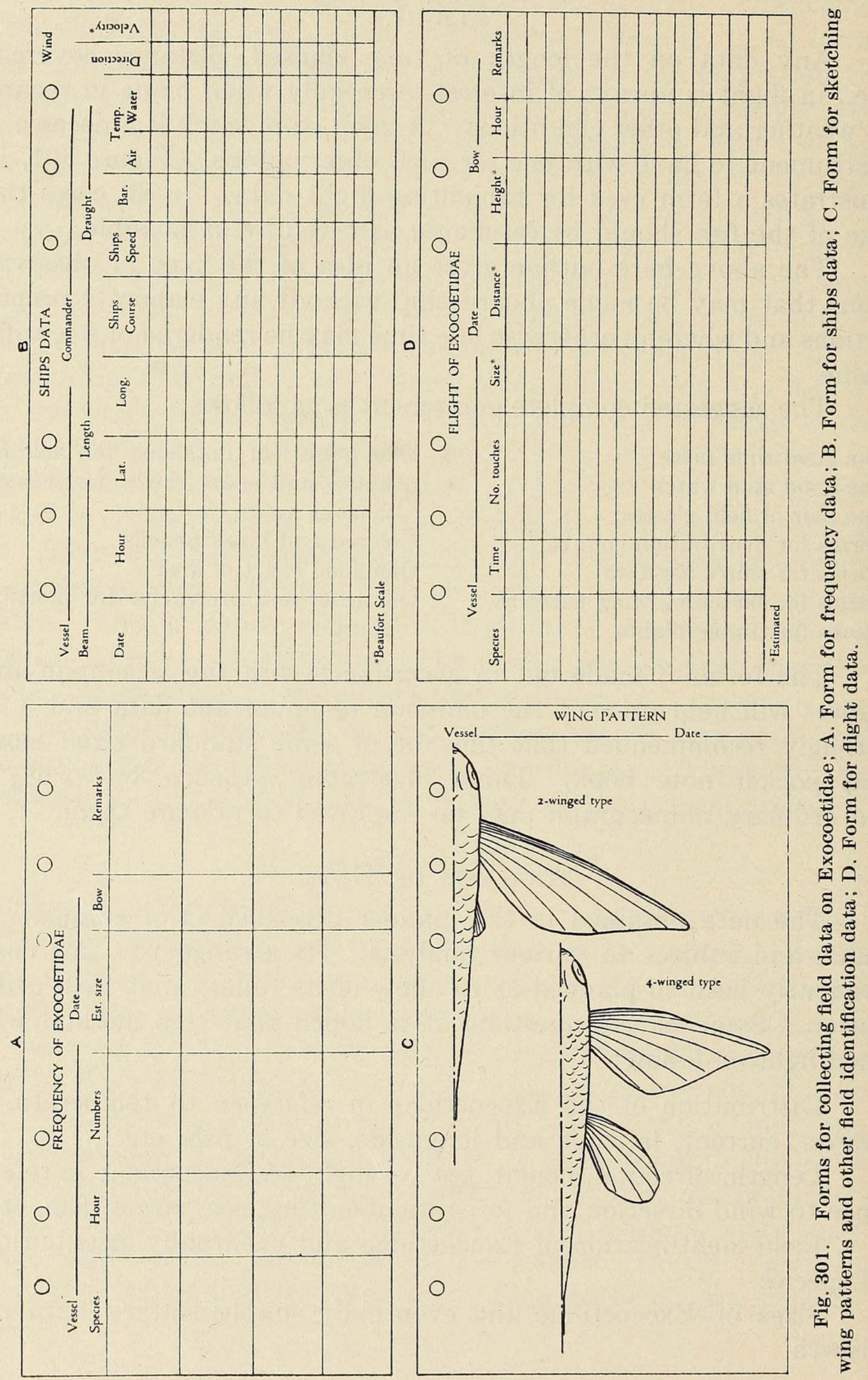
The following sections concerned with the actual data collected suggest various methods of analysis.

\section{Exocoetid Distribution in the Gulf Stream}

Observation stations to the number of 21 were made in various places between Latitudes $30^{\circ} 56^{\prime}$ to $37^{\circ} 14^{\prime} \mathrm{N}$. and Longitudes $80^{\circ} 57^{\prime}$ to $74^{\circ} 40^{\prime} \mathrm{W}$. The basic data derived therefrom is given in Table I. The columns covering wind velocity and direction, barometer, temperature, ship's course and ship's speed were all taken from the logs of the vessels. ${ }^{2}$

The wind direction is given in reference to the course of the ship, its angle of incidence in degrees being given under the side of the ship that was to the windward. The latitudes and longitudes are taken from the chart plotted from ship's log data, time and the ship's speed from the last observation locating the point. The periods of observation were all one-half hour and the time given is that when the change was made from port to starboard ( $i$. e. the middle point of each full observation period). The observations No. 4 to 10 inclusive were made by two observers ${ }^{3}$ jointly so they represent actually twice as long an interval ( $i$. $e$. one manhour of continuous observation). This must be taken into consideration in the calculations.

From this data an index of the number of fish inhabiting a given stretch of ocean water may be obtained. After some consideration it was decided that for most purposes the Exocoetid population might best be expressed in number per square nautical mile. These figures are given in the last column, "calculated population." It might be objected that only a certain percentage of fishes fly. While we have no way of determining what this percentage is at present it is reasonable to assume that under similar conditions similar percentages do fly. Just what this number bears to the actual population we of course do not know, but at the very least we have accurate figures of the flying population which of itself is of significance. The manner in which these figures are calculated follow.

\footnotetext{
${ }^{2}$ Appreciation is here expressed to Commander B. W. Leek and Chief Engineer C. P. Kennedy of the S. S. Algonquin and to Commander F. G. Avery and Firsi Officer J. A. Ohlund of the S. S. San Jacinto for their coöperation in supplying this data.

${ }^{3} \mathrm{I}$ am indebted to Mr. J. J. Shea for assisting in this matter as well as others bearing on the field work.
} 


\begin{tabular}{|c|c|c|c|c|}
\hline \multicolumn{3}{|c|}{ 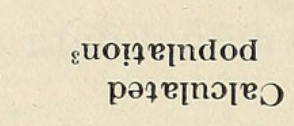 } & 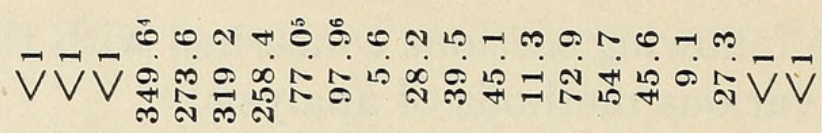 & d્ \\
\hline \multirow{2}{*}{\multicolumn{2}{|c|}{ 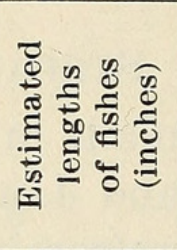 }} & $\cdot \mathrm{A}+\mathrm{S}$ & 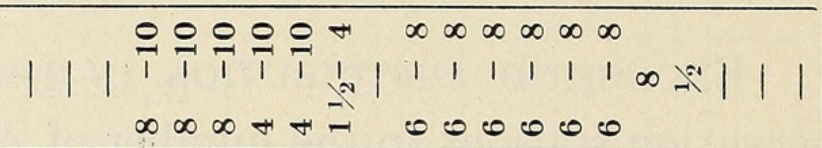 & \\
\hline & & $7.10 \mathrm{~d}$ & 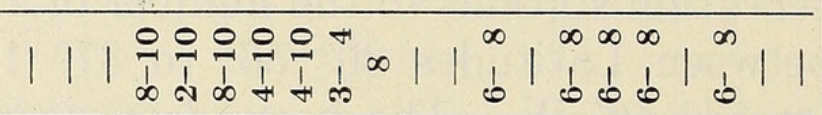 & \\
\hline \multirow{2}{*}{\multicolumn{2}{|c|}{ 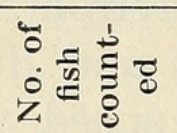 }} & $\cdot x+1 S$ & 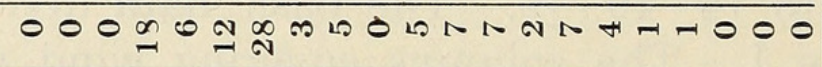 & \\
\hline & & $7.10 \mathrm{~d}$ & 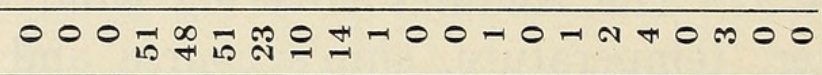 & \\
\hline \multicolumn{3}{|c|}{$\begin{array}{l}\text { (słouy) } \\
\text { pəəds s،d!us }\end{array}$} & 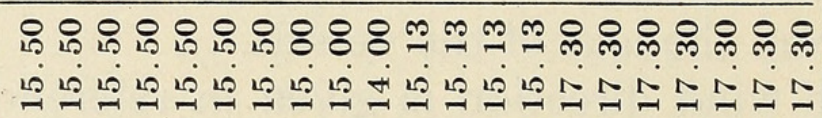 & \\
\hline \multicolumn{3}{|c|}{ әsınoว s، d!̣ } & 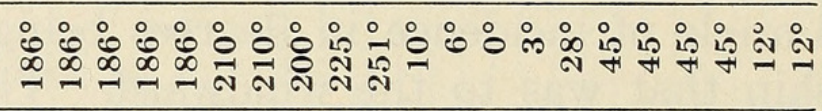 & \\
\hline \multicolumn{3}{|c|}{ 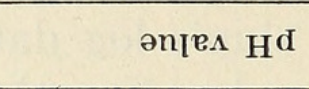 } & 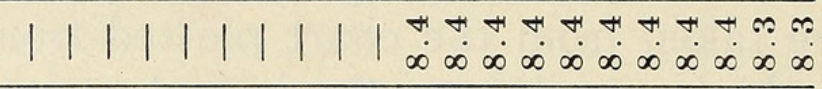 & \\
\hline \multicolumn{3}{|c|}{ 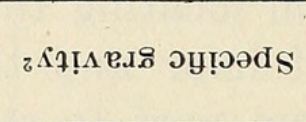 } & 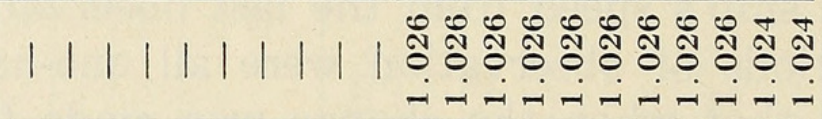 & \\
\hline \multirow{2}{*}{$\underset{\mathrm{g}}{\stackrel{0}{0}}$} & \multicolumn{2}{|c|}{ Іәәе $\mathrm{M}$} & 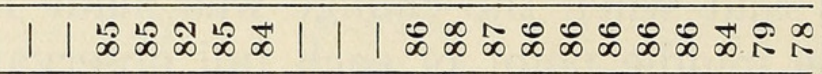 & \\
\hline & \multicolumn{2}{|r|}{ I!Y } & N & \\
\hline \multicolumn{3}{|c|}{ ләдәшо.яеg } & 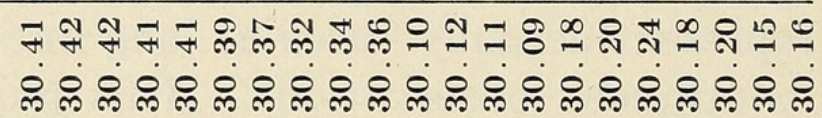 & \\
\hline \multirow{3}{*}{ 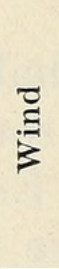 } & \multirow{2}{*}{ 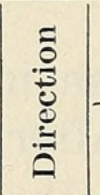 } & $\cdot 2+\mathrm{T}$ & 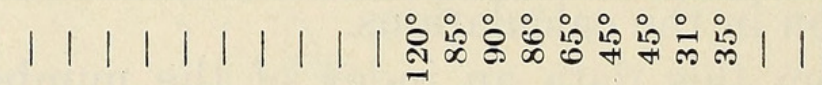 & \\
\hline & & $7.10 \mathrm{~d}$ & 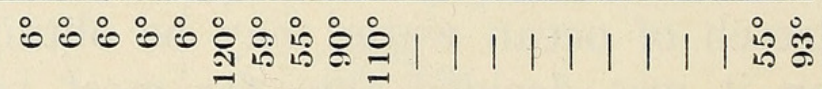 & \\
\hline & & $\mathrm{I}^{\top} \partial_{\Lambda}$ & 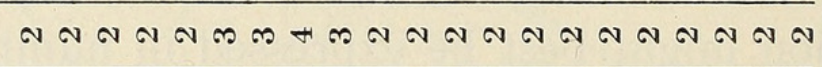 & \\
\hline \multicolumn{3}{|c|}{ 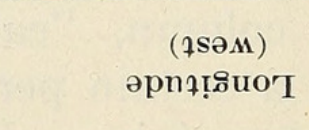 } & 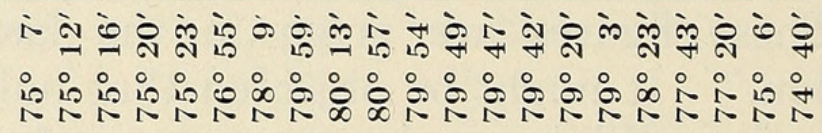 & \\
\hline \multicolumn{3}{|c|}{ 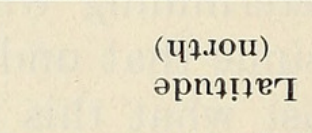 } & 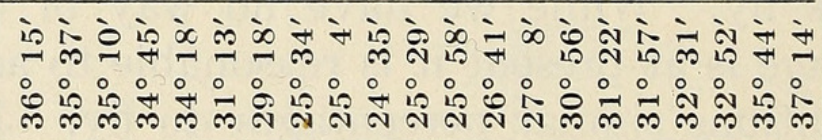 & \\
\hline \multicolumn{3}{|c|}{ 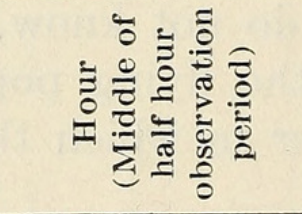 } & 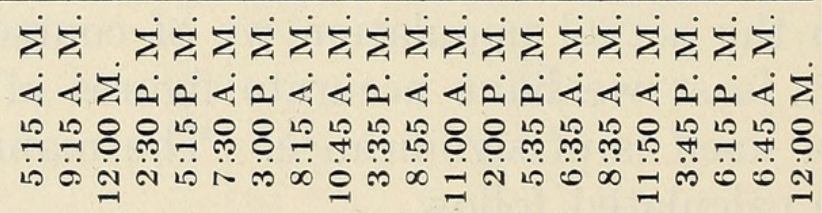 & \\
\hline \multicolumn{3}{|c|}{$\stackrel{7}{2}$} & 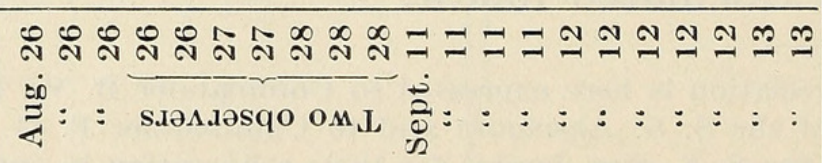 & \\
\hline \multicolumn{3}{|c|}{ 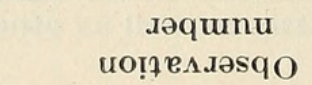 } & & \\
\hline
\end{tabular}


Let:

Speed of ship in knots per hour

Time of observation in decimals of an hour $=\mathrm{T}$

Beam of ship in feet $=B$

Width of area of disturbance on one side of ship in feet $=\mathrm{D}$

Number of fish observed $\quad=\mathrm{F}$

Population per square nautical mile $=\mathrm{X}$

Since there are 6080.2 feet in a nautical mile the following formulae may be used.

Then:

$$
\begin{aligned}
& \frac{6080.2 \cdot F}{(2 \mathrm{D}+\mathrm{B}) \cdot \mathrm{T} \cdot \mathrm{K}}=\mathrm{X} \text { for two observers. } \\
& \frac{6080.2 \cdot \mathrm{F}}{\left(\mathrm{D}+\frac{\mathrm{B}}{2}\right) \cdot \mathrm{T} \cdot \mathrm{K}}=\mathrm{X} \text { for one observer. }
\end{aligned}
$$

Below are given the actual calculations involved.

The beam of the ship plus the area disturbed on either side is the width of the area scanned. The latter is estimated by observation of the ship underway and is located at the curl of the bow wave (see Figure 302). In average large vessels this is usually situated about $50^{\prime}$ from their side.
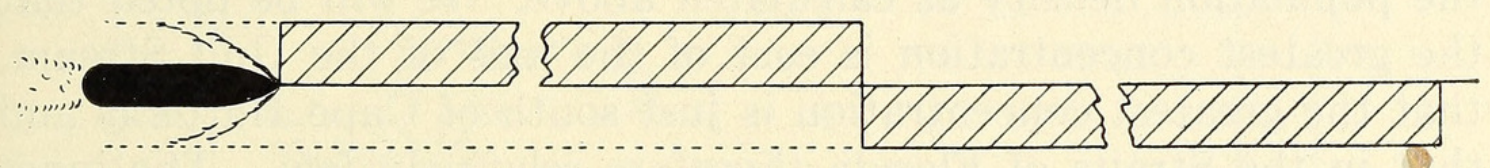

Fig. 302. Diagram of areas of observation for frequency data. The ship is in the position for the initiation of an observation period. The hatched area just ahead of the ship represents the port watch, say of 15 minutes, and the succeeding area the starboard watch of identical length. With two observers both sides of the ships course would be under observation. The width of the area is determined by the lateral extent of the disturbing bow wave as indicated.

Fishes arising at a distance greater than this from the vessel are considered as flying from other causes and are not counted. In other words the width of the area considered is $2 \mathrm{D}+\mathrm{B}$ for two observers or $\mathrm{D}+\frac{\mathrm{B}}{2}$ for one. Time of observation in decimal fractions of an hour multiplied by the knots per hour multiplied by 6080.2 gives the length of the band scanned in feet. Multiplying 
these the resulting figure divided into the square of 6080.2 gives the number of such parts contained in a square nautical mile. This multiplied by the number of fish observed in the sample area gives the estimated population per square nautical mile. The full formula would read.

For two observers

$$
\frac{36968832.04}{(2 \mathrm{D}+\mathrm{B}) \cdot \mathrm{T} \cdot \mathrm{K} \cdot 6080.2} \cdot \mathrm{F}=\mathrm{X}
$$

or for one

$$
\frac{36968832.04}{\left(\mathrm{D}+\frac{\mathrm{B}}{2}\right) \cdot \mathrm{T} \cdot \mathrm{K} \cdot 6080.2} \cdot \mathrm{F}=\mathrm{X}
$$

This is reducible to the following formula with which an example (the first calculation) is given.

$$
\begin{gathered}
\frac{6080.2 \cdot \mathrm{F}}{(2 \mathrm{D}+\mathrm{B}) \cdot \mathrm{T} \cdot \mathrm{K}}=\mathrm{X} \\
\frac{6080.2 \cdot 69}{(2 \cdot 50+54) \cdot 15.5 \cdot 0.5}=349.6
\end{gathered}
$$

Although no especial effort to analyze in full the data here presented is attempted, reference is made to (Fig. 303) which gives the population density as calculated above. It will be noted that the greatest concentration is east of the axis of the Gulf Stream, that the greatest concentration is just south of Cape Hatteras and that in the Straits of Florida there are relatively few. The inner edge of the Gulf Stream is similarly barren, that is very few find their way north or west of it. West of the axis the counts are all less than 100 per square mile and east of it (south of Hatteras and north of the Florida straits) all over 250. This of course may vary considerably from season to season, with prevailing winds, etc. It is for just this reason that continued observations of this nature are desirable.

While these distributional figures may not hold absolute accuracy or present any startling contribution to the present knowledge of Exocoetid distribution the value of the method, the extension into detail of their distribution and the following data is considered ample justification for the present paper. 


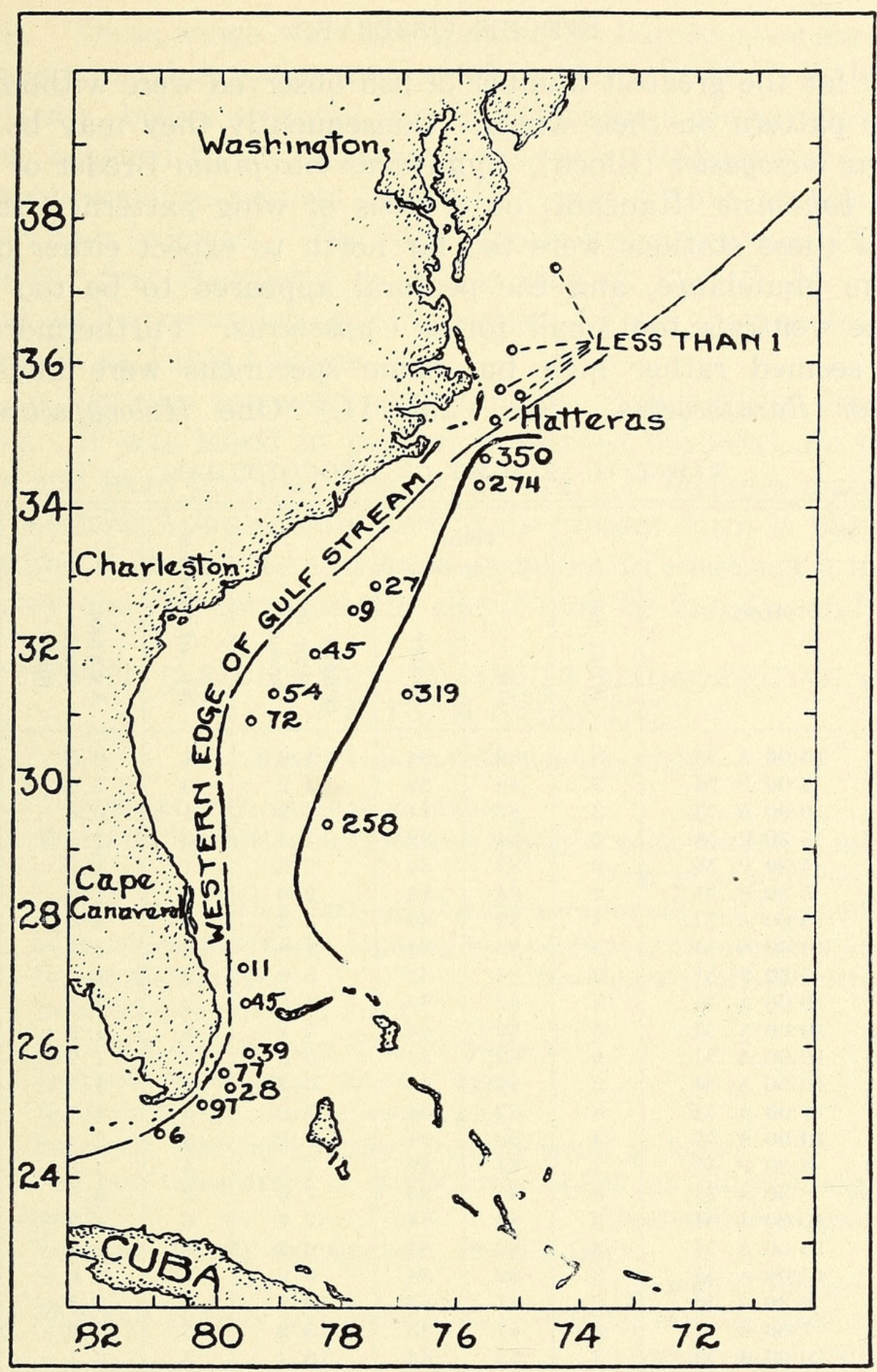

Fig. 303. Calculated population of Exocoetidae in the Gulf Stream, September 26th to August 13, 1928. See table I for details; the figures given at each station are the nearest whole numbers of fish per square nautical mile as calculated from Table I. The heavy solid line separates the areas with a population of over 250 fish per square mile from those of under 100. This line in its northeast trend approximates the axis of the Gulf Stream. Past the western edge of the Gulf Stream none were counted during periods of observation. Consequently these are calculated as less than one per square mile. 


\section{SPECIES OBSER VED}

By far the greatest number of fish observed were without any definite pattern on their wings. Consequently they may be Parexocoetus mesogaster (Bloch), Cypselurus vitropinna Breder or Cypselurus bahiensis (Ranzani) on a basis of wing pattern, although most of these stations were too far north to expect either of the latter in abundance, and the pectoral appeared to be too short and the ventrals too small for a Cypselurus. Furthermore the dorsal seemed rather high but some specimens were unusually large for Parexocoetus. (See Table II.) One Halocypselus was

TABLE II. FLIGHT OF EXOCOETIDAE

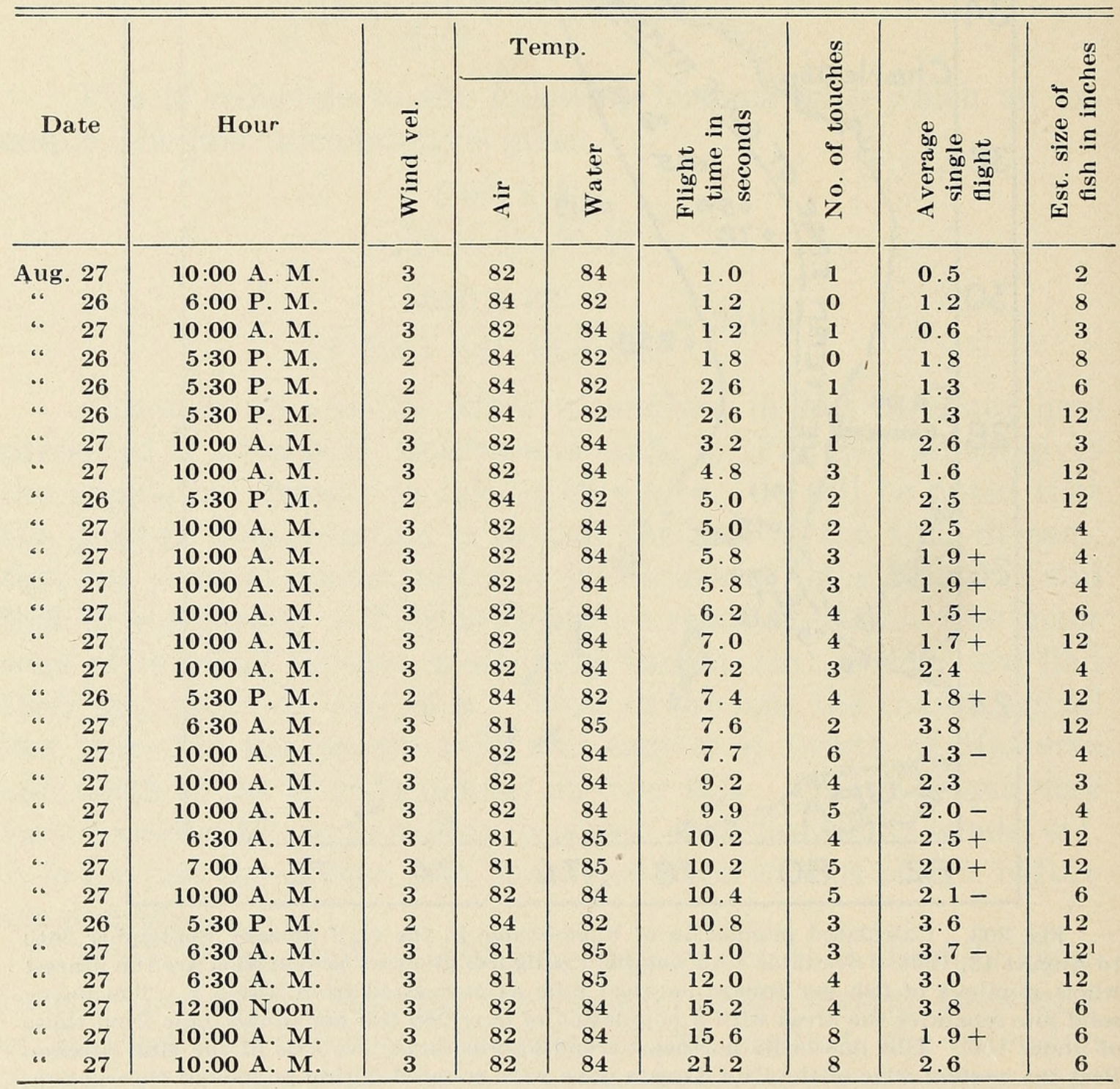

I Possibly Hirundichthys rufipinnis (Cuvier \& Valenciennes) (Pectorals dusky, ventrals plain). Refer to Table I for other data. 
seen. Those which were not apparently Parexocoetus are indicated in the two tables. On August 26th, 11:10 A. M., a little north of Hatteras, before entering the Gulf Stream a single specimen was seen, believed to be Cypselurus heterurus (Rafinesque). The first two observation periods before this were blanks as was the next one which followed. The Gulf Stream was entered at 12:05 P. M. and the first Exocoetid in it was seen at 1:50 P. M. This was what we here consider as Parexocoetus. From then on they became common as Table I shows.

A key was prepared to aid in identifying flying fishes on the wing. It was based in part on preserved material, on the literature and from previous field experience. It includes material from the western Atlantic only and in its present form is purely tentative and is given here as a basis on which to construct a more satisfactory one and for whatever else it may be found useful.

\section{TENTATIVE FIELD KEY TO ADULT EXOCOETIDAE OF THE WESTERN ATLANTIC}

\section{BASED LARGELY ON WING PATTERN}

A. Two wings only, evident in flight.

B. Wings dusky, with a light area on posterior edge, darkest at anterior edge. Halocypselus evolans (Linnaeus)

BB. Wings clear, with a dark spot on the anterior edge and a band near distal edge, widest anteriorly, tapering to a point near the posterior edge, parallel to the distal edge.

Halocypselus obtusirostris (Gunther)

AA. Four wings evident in flight.

C. Pectorals without any distinct pattern.

D. Pectorals transparent or very light.

E. Ventrals transparent or very light.

F. Pectorals very light dusky; ventrals small or large.

G. Ventrals transparent or sometimes reddish on anterior edge; ventrals small.

GG. Ventrals entirely transparent; ventrals large.

Parexocoetus mesogaster (Bloch)

Cypselurus bahensis (Ranzani)

FF. Pectorals entirely transparent, also ventrals; ventrals large.

Cypselurus vitropinna Breder

EE. Ventrals dusky, darkest at tip and lightest at base; pectorals light dusky; ventrals large

Prognichthys gibbifrons (Cuvier \& Valenciennes)

DD. Pectorals gray or darker for most part; ventrals large.

H. Ventrals transparent, pectorals darkest distally, lightest proximally.

HH. Ventrals dark.

Hirundichthys rufipinnis (Cuvier \& Valenciennes)

I. Ventrals uniform dusky; pectorals dusky. 
J. Pectorals darkest mesially and with a vague transparent margin on the posterior edge; 2 long mandibular barbels.

Cypselurus monroei Nichols \& Breder

JJ. Pectorals and ventrals uniform dusky; no barbels.

Cypselurus lineatus Cuvier \& Valenciennes

II. Ventrals darkest mesially, with a light axil and a light tip; pectorals uniform dusky except for a scarcely evident distal edging of transparent. (Young $=E$. exsiliens Muller?)

Exonautes rondeletii Cuvier \& Valenciennes

CC. Pectorals with a distinct and sharply defined pattern of black and transparent.

K. Pectorals dark with a broad transparent band running diagonally entirely across fin.

L. Ventrals dark, with a broad transparent band similar to pectorals; pectorals also with a scarcely evident transparent distal edging.

Cypselurus furcatus Mitchill

LL. Ventrals transparent except for a dark axil; pectoral tip also transparent. Cypselurus heterurus Rafinesque

KK. Pectorals dark, with a broad transparent band running diagonally from the posterior edge of fin but not entirely across it.

M. Ventrals uniform dusky, pectoral bar reaching less than half way across fin.

Hirundichthys vinciguerrae (Jordan \& Meek)

MM. Ventrals transparent, except for dark axil.

N. Pectorals uniform dusky except for a transparent bar which reaches about $3 / 4$ way across fin and a very narrow transparent edging.

Hirundichthys affinis (Gunther)

NN. Pectorals darker distally than proximally, transparent bar not reaching more than half way across fin, no transparent edging.

Cypselurus lutkeni Jordan \& Evermann

\section{FACTORS INFLUENCING FLIGHT}

As has been noted a shift from one bow to the other was made in all cases to prevent any possible bias. The importance of this method of procedure is brought out by the fact that in practically all cases there was a marked difference in the numbers counted on either side both in consecutive counts by a single observer and in simultaneous counts by two observers. If we consider the factors that may act differently on one side of a ship than the other it at once becomes evident that wind, wave motion and sunshine are about the only ones that can be readily dealt with. As in midocean generally, in fair weather, the wind and the sea ran together. When these observations were made the "ground swell" was practically absent and could not be correlated with any observed phenomena. If we consider the wind and wind-impelled wave action 
we find that the flying fish flew in a very direct response to it. Totalling those from the windward side we get 230 and those from the lee 85 or in other words nearly three times as many flew into the wind as with it. A comparison of the angle of incidence with the ship's course failed to bring out any more exact relationship, nor did the numbers flying show any correlation with that angle. A greater amount of data might well be expected to show a close connection.

It seems natural enough for flying fish to fly into the wind, but how are these figures to be interpreted? Do they fail to fly if "chased" with the wind? Do they know before leaving the water what direction the wind is blowing and orient themselves accordingly, if possible? Is this from recent memory? If so, it would seem that they fly a great deal more than one would gather from observations aboard ship. Those that do fly with the wind generally do not have such long flights as those against or across it. This observation is in direct contradiction to that of $\mathrm{Hubbs}^{4}$ who writes as follows of Cypselurus californicus " . . . when flying with the wind, distances of about a quarter mile are occasionally made." This difference may be due to weather conditions or specific habits as this paper is one of the few recent ones on the subject that carries the conviction of careful and accurate observation with it.

Frequently they do little more than plunge out and in again. The only directing influence the wind above could have on the submerged fish is from motion imparted to the water by it. Considering the directive effect that wind-produced waves might have on flying fish about to immerge we may better contemplate the conditions by reference to (Fig. 304). Here is shown the emergence of a flying fish against and with the wind. The waves move in the direction of the horizontal arrow but the water as a mass is stationary except for a moment of the particles in an elliptical path somewhat as shown by the curved arrows. Thus the surface layer moves actually with the wind under the crest of a wave and against it in the trough. Hypothetically a flying fish coming up from relatively still water below could orient itself to swim with the flow of water and then cut into a reverse flow immediately before breaking the surface. This might explain choice in flight, especially as

${ }^{4}$ Hubbs, C. L. Copeia No. 62, 1918, pp. 85-88. 

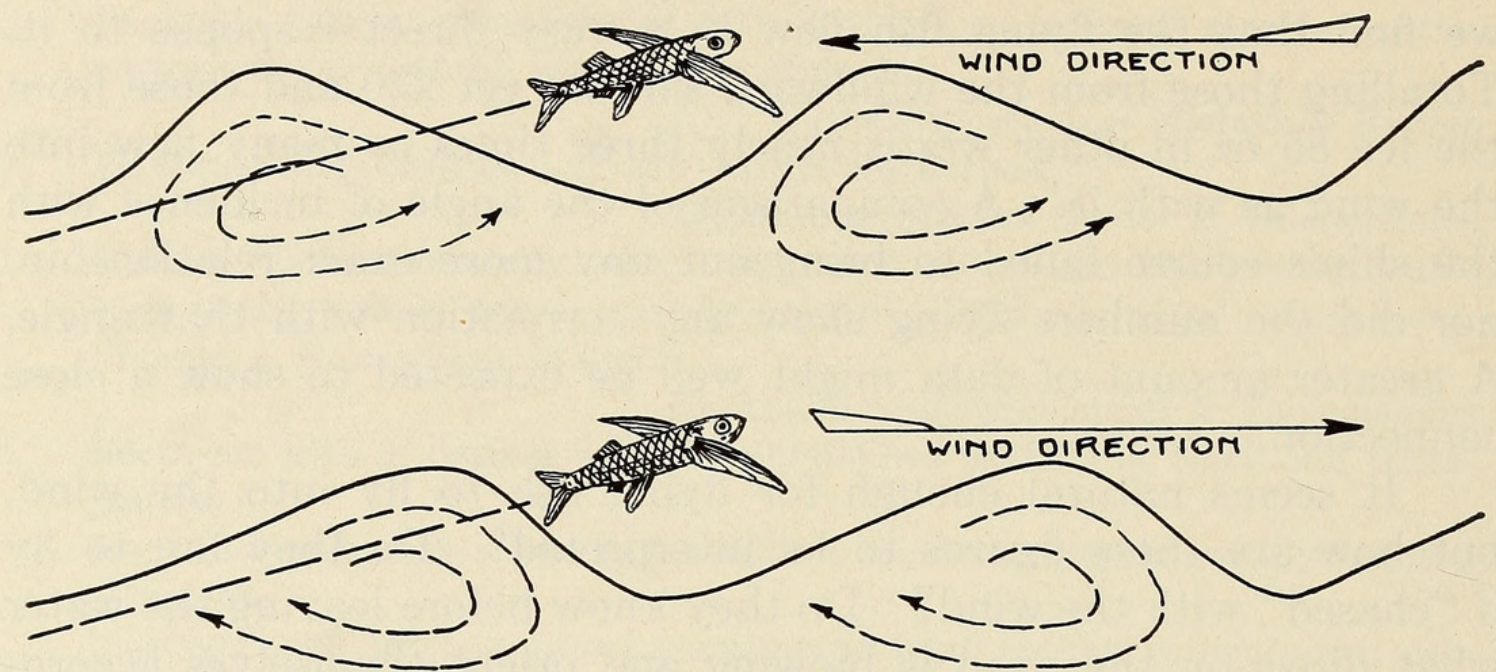

Fig. 304. Wind direction and Exocoetid flight. The upper diagram shows immergence from the windward side of a wave indicating motion of water particles, form of wave, direction of wind and wave motion. The lower diagram shows immergence from the leeward side of a wave indicating the same factors.

flying fish probably normally inhabit a stratum not far below the surface. In the opposite case a reverse flow might discourage attempts to fly. That this manner of exit is advantageous there can be little doubt. In the first case the rear side of a wave is usually the point of taking off (a matter of observation) and allows the fish to be suddenly left suspended in air in a clean-cut take-off. In the other case the wave follows along and the speed of leaving the water is slower. They may be compared as follows: water.

Into the wind; Speed of fish + speed of wave = speed of clearing

With the wind; Speed of fish - speed of wave = speed of clearing water.

Coupled with this is the advantage in the first case of such an object (rather comparable to a toy aeroplane) taking off into the wind.

While the above hypothetical considerations are not necessarily true in their minutest detail it follows on evidence quite a priori that some such effect must exert its influence to cause the observed difference in counts from side to side of a vessel.

Hubbs $l$. $c$. writes as follows of Cypselurus californicus. "They appear never to leap directly into the air, as some species are said to do but, on emerging from the water with greater or less velocity 
they immediately spread their wide pectoral 'wings' and move forward on the surface like tiny aeroplanes, for a distance averaging perhaps twenty-five feet." The species considered in this paper, supposedly Parexocoetus, certainly do not average twentyfive feet of skittering on their emergence. ${ }^{5} \quad$ Many probably average about five feet and a large number leave directly as discussed above. Considering those which do not leave directly there is not as great a difference as might first appear. With the forepart of the body emergent they skull along with the tail in the water and follow the curved surface of the moving waves but the eventual take-off is normally from just beyond the crest of some wavelet in about the position shown (Fig. 304) or a little nearer its crest. It is here that the ventrals are spread, raising the tail clear of the water.

During this period of skulling much greater velocity is acquired than these fish could possibly be expected to gain under water for, as pointed out by Breder ${ }^{\text {" } ~ . ~ . ~ . ~ . ~ t h e ~ p e c t o r a l s ~ r a i s e ~ t h e ~ w e i g h t ~}$ of the head and forepart of the body into the air, leaving the tail submerged. The bulk of the fish being in the air reduces head resistance considerably, while the tail still has the advantages of operating in the denser medium."

What then becomes of the fish that do not fly to the leeward? Two possibilities can be thought of. They may simply swim out of the way as do other fish. If so they would be expected to be seen more often in the clear Gulf water that does not obscure other fishes of similar size. The other possibility is that they may scatter considerably in advance of the moving noisy hull and tend to the windward side so that when they are overtaken most are already on that side. If observations from a relatively silent sailing vessel do not show such marked differences this thought would be much strengthened. It is for the above reasons that the statistical population is considered merely relative and that no attempt is made to weigh the observations for a more absolute determination.

We may now consider the effect of light; in this case sunshine. During all of these observations the sun shone brightly and as flying fish are known to throw themselves at lights at night as do other fishes, the possibility of the sun as a direct source of directive

5 This is very probably associated with the average size of the two species.

${ }^{6}$ Breder, C. M., Jr. The Locomotion of Fishes. Zoologica Vol. IV, No. 5, 1926. p. 159-297. 
influence must be considered. As the wind blew continually across one bow and the days split between having the port and starboard alternately illuminated it should become relatively easy to separate the two influences. If we total those observed on the sunny side we get 155 and those on the shady side 160 . This of course is very little difference with a slight suggestion of their flying away from the light. This, however, is hardly a fair way to analyze this data, as in cases where the sun is high little influence could be expected. This is a point which the present data is inadequate for and which further observations should clear up.

If a stop watch is held on the length of time flying fish stay aloft it will be found that they vary from the shortest possible aerial excursions to those of considerable length. The sixth column of Table II gives the flight time in seconds of the 29 observations made. As usually flying fishes drop their tail into the water to gain an added thrust these drops are given in the seventh column. The eighth column gives the result of dividing the second into the first. These figures give an index of the time between hops. They include, however, such time as is spent in skittering over the surface for the next rise. It is evident from these figures without the necessity of graphic plotting that, on the average, the longer the flight the more often the tail drops for added momentum but that these do not increase at as fast a rate is shown by the seventh column in which the time between tail drops average longer in the longer flights. The exact meaning of this is not entirely clear but suggests that size of fish and initial momentum has something to do with it. The correlation between estimated size and length of flight is not very great but that one exists is evident if the average of the first half of the column is compared with that of the last splitting between 7.2 and 7.4 seconds. Those flying less than 7.4 seconds averaged $6.66+$ inches in length and averaged $1.68+$ seconds per single flight while those above that average 8.5 inches and 2.8 seconds per single flight.

Captain B. W. Leek of the S. S. Algonquin stated that he had often held a stop watch on flying fishes and although he had not recorded the results that at one time he had clocked one at 42 seconds in a light breeze and calm sea. This is probably near the maximum for fishes of this general locality.

A study of the present data in regard to schooling indicates 
merely that where flying fish are most abundant they tend to form the largest schools. Naturally enough the largest schools were noted to the windward side. The largest was composed of 25 fish. On the lee side but one school included more than 5, one of 15 . On the windward were noted 8 schools of more than 5 , of from 6 to 25. These notes refer only to observations during the stated intervals. About 34 per cent. of fishes so observed flew singly, 14 per cent. in twos, 6 per cent. in threes and so on. In other words about twice as many flew in company as alone.

A caution is here given concerning observations on the direction of flight in reference to that of the wind. Viewed from aboard a moving ship it is very easy to forget the complicating effect of the observer's own motion. The solid curved line of flight (Fig. 305)

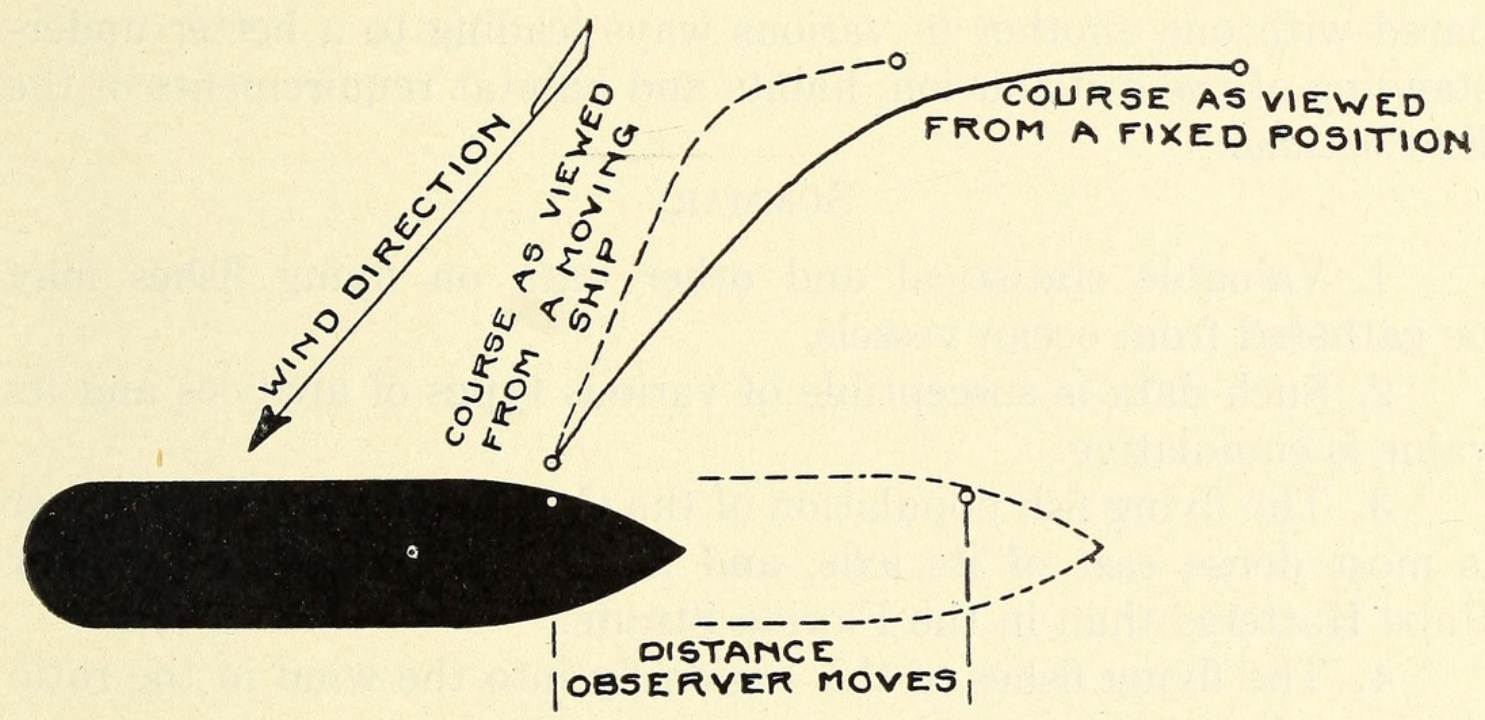

Fig. 305. Diagram showing a typical exocoetid flight with regard to wind direction and the apparent differences due to the forward motion of the observer which must be considered in the study of the relationship to flight and wind direction.

represents a typical course, starting directly into the wind and finally ending at an angle to it. Due to the observer's motion however the course will more nearly resemble that of the dotted line at no time parallel to the wind direction.

In conclusion it is pointed out that only a suggestion has been given here of the possible analysis that these figures may be given. This is partly because the data so far collected is inadequate and partly because this paper is intended primarily to lay a method of study before ocean travelers. A list follows of the more evident types of analysis that an adequate number of observations might be given. 
Species

Sizes of individuals

Flight characteristics

length

height

speed

direction

form

Geographic locality

Time of day

Season

Meterological conditions

Temperature

Wind

\author{
direction \\ velocity \\ Sunshine \\ direction \\ intensity \\ Water conditions \\ Temperature \\ Current \\ speed \\ direction \\ Wave action \\ Salinity \\ $\mathrm{pH}$ value
}

Each of the above items and their sub-items could be compared with one another in various ways leading to a better understanding of the distribution, habits and habitat requirements of the Exocoetidae.

\section{SUMMARY}

1. Valuable statistical and other data on flying fishes may be gathered from ocean vessels.

2. Such data is susceptible of various types of analysis and its value is cumulative.

3. The flying fish population of the Gulf Stream in late summer is most dense east of its axis, and north and south, denser near Cape Hatteras than in the Florida Straits.

4. The flying fishes of this region fly into the wind in the ratio of about 1 to 3 .

5. The only directive influence from the wind they are able to feel is that due to the underwater disturbance of wind-impelled waves.

6. The direction of sunlight may have secondary influence on their flight.

7. The larger the fish, on the average, the longer the fligth will be and the fewer the dippings of the tail into the water for added power.

8. About twice as many flying fish fly in schools of two or more as fly alone.

9. Parexocoetus mesogaster is the predominant form in the Gulf Stream. 


\section{$2 \mathrm{BHL}$ Biodiversity Heritage Library}

Breder, Charles M. 1929. "Field observations on flying fishes; A suggestion of methods." Zoologica : scientific contributions of the New York Zoological Society 9(7), 295-312. https://doi.org/10.5962/p.203747.

View This Item Online: https://www.biodiversitylibrary.org/item/208079

DOI: https://doi.org/10.5962/p.203747

Permalink: https://www.biodiversitylibrary.org/partpdf/203747

\section{Holding Institution}

Smithsonian Libraries

\section{Sponsored by}

Biodiversity Heritage Library

\section{Copyright \& Reuse}

Copyright Status: In Copyright. Digitized with the permission of the rights holder

Rights Holder: Wildlife Conservation Society

License: http://creativecommons.org/licenses/by-nc/3.0/

Rights: https://www.biodiversitylibrary.org/permissions/

This document was created from content at the Biodiversity Heritage Library, the world's largest open access digital library for biodiversity literature and archives. Visit BHL at https://www.biodiversitylibrary.org. 